\title{
ENHANCING THE STABILITY OF THE TIMBER HARVESTING MACHINE OF MANIPULATOR TYPE BY USING AN ACTIVE SUSPENSION SYSTEM
}

\author{
Bogdanov Evgenii Nikolaevich* \\ Volga State University of Technology, Russia \\ Dr Bagautdinov Ildar Nyrgaiazovich \\ Volga State University of Technology, Russia \\ Zhilin Stepan Sergeevich \\ Volga State University of Technology, Russia
}

The paper represents technique and calculation of the timber harvesting machine stability when using an active suspension system that leads to enhancement of stability and productivity increase at the expense of safe work.

Key words: Mathematical modeling, Feller buncher, Manipulator, Undercarriage frame, Stability

\section{INTRODUCTION}

Modern timber harvesting machine of manipulator type still remains most perspective machine in timber harvesting mechanization for the nearest future. For tree-length method the most efficient machine is considered the feller buncher LP-19V from the home manufacturers. The main determining factor of timber harvesting machine efficiency, while using it in logging area is its productivity. LP-19V productivity at present has almost reached its maximum value. Further increase is possible only if constructive parameters and technological equipment would be changed. That is, using accumulators, increasing load capacity, or if time of technological cycle would be decreased. It can be achieved by acceleration of working attachments. Acceleration of working attachments leads to dynamic loads, which in turn, can cause stability loss of the vehicle at work. Moreover, the machine works on unlevel surface most of the time. Stability loss can cause overall and decrease the machine productivity. There are different methods how to determine stability of modern lifting machines (mobile and stationary). The main document is "Regulations on Installation and Safe Operation of Cargo Cranes" [01], so called, "Regulations of Federal Mining and Industrial Inspectorate of Russia", GOST 13994-81 "Construction tower cranes. Calculation standards". For diggers the method of Kirov digger plant [02] is used as well as VNIISTROYDORMASH method, Karasevzhiveynov technique $[03,04,05]$ and, moreover, we can use a method of stability evaluation and load capacity determination for hydraulic diggers according to German standards (standard DIN 24087-79 "Earth-digging machines. Hydraulic diggers' stability. Safety requirements". They refer to diggers, that perform earth works, but not for load lifting.

Research objectives: stability augmentor of a feller buncher LP-19V, due to productivity improvement and, as a result, its competitive growth on the international market in comparison with machines of foreign manufacturers [06].

The authors of the given research consider one of the ways of stability augmentor of feller buncher LP-19V modernization of suspension system by using active base with reverse track $[07,08]$, which leads to stability improvement and, as the result to better efficiency.

\section{RESEARCH METHOD}

This paper represents the computing only in statics (that's quite sufficient in order to check working capacity at the stage of conceptual design as well as for feasibility of further engineering design). The most frequent technological operation of a feller buncher is carrying the cut tree. This operation influences the machine stability considerably.

In the course of modeling, we carry out a research of manipulator motion pattern with work object from the back part of the machine (point c0, Figure 1) to the front part (point $\mathrm{c} 8$, figure 1). This motion allows simulating hardest load conditions in various manipulator positions with the work object.

$$
K_{u s t}=\frac{M_{u d}}{M_{o o}},
$$


where $\mathrm{M}_{\mathrm{ud}}$ - stabilizing moment, keeping machine from overall [HM], - moment from outer and inner forces and weights which tend to overall the machine with respect to an overall point $[\mathrm{HM}]$.

$$
M_{u d}=G_{p p} \times L_{p p}+G h_{o d} \times L_{h o d} \pm P_{v} \times h_{b}
$$

where $G_{P P}$ - is the weight of rotating platform, $\mathrm{H}$; $L_{P P}$ - the distance from rotating platform weight center to pivot axis, $\mathrm{M} ; \mathrm{G}_{\mathrm{HOD}}$ - carriage frame weight, $\mathrm{H} ; L_{H O D}$ - distance from carriage frame weight center to pivot axis, $\mathrm{M} ; \pm P_{v}$ - wind load, $\mathrm{H}$ ( \pm - shows that wind direction can change and

conduce or resist overall); $h_{b}$ - distance from the wind load application point to the ground surface, $M$.

The overall moment with respect to an overall point is found from the formula:

$$
M_{o o}=G_{S t r} \times L_{S t r}+G_{g p} \times L_{g p}+G f h \times L f h+G_{d e r} \times L_{d e r} \pm P_{v} \times h b
$$

where $G_{s t r}$ - manipulator arm weight, $\mathrm{H} ; L_{s t r}$ - distance from manipulator arm weight center to pivot axis, $M ; G_{g p}$-weight of manipulator's hydraulic drive, $\mathrm{H} ; L_{g p}$ - distance from the weight of manipulator's hydraulic drive center to pivot axis, $M ; G_{f h}$ - weight of the felling head, $\mathrm{H} ; L_{t h}$ - distance from the center of the felling head weight to pivot axis, M; $G_{d e r}$-tree weight, $H ; L_{d e r}$ - distance from the tree weight application point to the pivot axis, $M$.

The modeling is performed in order to find the stability of the existing feller buncher LP-19V and for the advanced model LP-19M (with carriage frame under development and augmented stability) in various manipulator positions in relations to carriage frame.

For this purpose it is necessary to determine stability coefficient, which is principal in comparison with different suspension systems of the machine.

The overall point will vary at any time while the manipulator arm turns and carries the tree to another place (the angle change $\alpha$, figure 1).

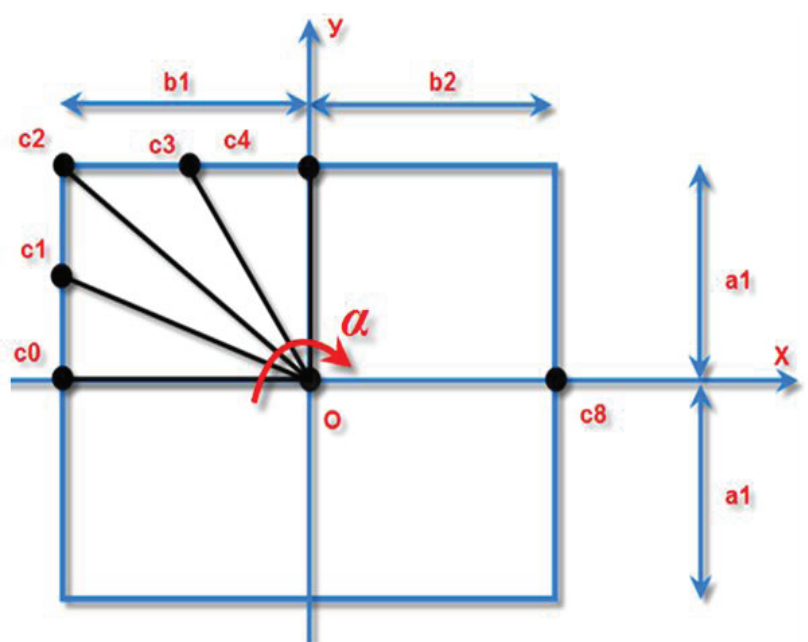

Figure 1: Analytic model of determination the overall point while manipulator turns to carry a tree.
In other words the distance from overall point of all weights centers will be variable. It means that all output parameters will be changed and, what is most significant, the stability coefficient will be changed either. At that, the overall point moves about some rectangle - overall perimeter (figure 1), depending on manipulator position against the carriage frame.

Figure 1 represents $\mathrm{c} 0, \mathrm{c} 1, \ldots, \mathrm{ci}$ - overall point position in the respect with manipulator position (turn angle of the rotation platform); a1, b1, b2 - geometrical parameters of the overall sector perimeter (rectangle sides).

Overall sector goes along the base of suspension system and that is why it is dependent on the suspension system type of the given machine.

The sector perimeter is determined according to bility system. The existing feller buncher LP-19V has balancing-lever with four-point suspension.

Figure 2 shows overall sector parameters for the existing LP-19V. It is obvious that transverse stability of the given construction is higher than in the front or back position of the manipulator.

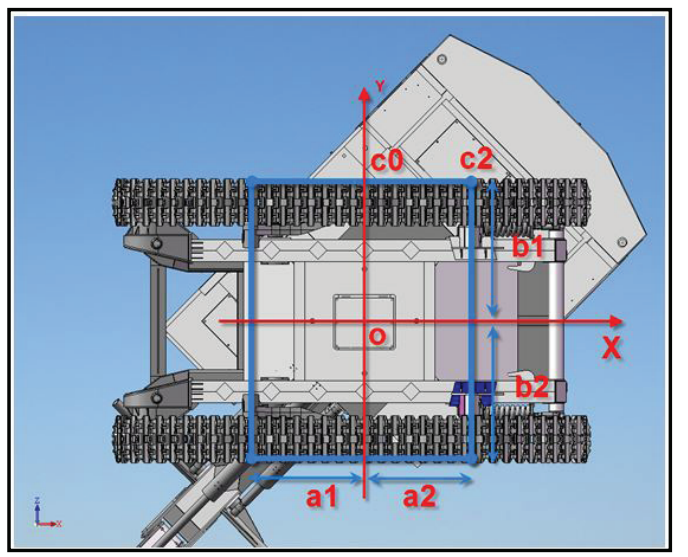

Figure 2: Overall sector parameters for the existing LP-19V suspension system. Bottom view. connection points of the carriage frame with mo- 
We propose to undertake the research aimed to study the question of how to increase stability of LP-19V at work, while using some original projects corresponding to the patents №2491201, 127356 and some applications for invention, by means of overall sector change on the basis of installation of various suspension systems $[07,08]$.

Foreign manufacturers apply digger undercarriage systems in timber harvesting machines. These systems have rigid (non-balancing) suspension systems. When digger undercarriage system is mounted on LP-19V, its overall point moves in axis direction of the machine. It increases the machine stability significantly, both in front and back manipulator positions (Figure 3).

Furthermore, in an effort to increase the machine stability, it is provided to change track frames position. It is achieved by changing the machine's track pit using telescopic moving out mechanism $[07,08]$. When we use the data of original proj-

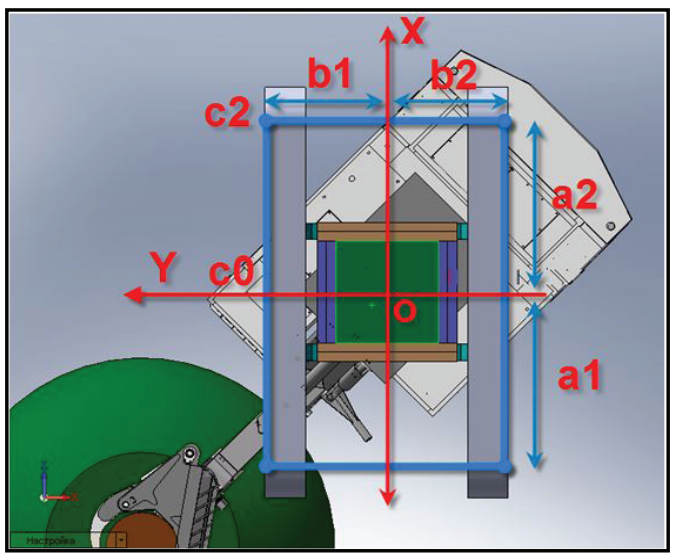

Figure 3: Overall sector parameters of the $L P-19(d)$ digger suspension system. Bottom view. ects, the machine stability increases, due to the track pit enlargement (Figure 4).

In this way, studying overall point position $\mathrm{c} 0, \mathrm{c} 1$, ... c8 (Figure 1) around the central axis, that passes through point $\mathrm{O}$, we can find the distances Oc0, Oc1, ... Oc8, which, in their turn, will vary in accordance to the applied suspension system type.

\section{CALCULATION RESULTS}

If we insert initial values [09] into obtained formulae and change variables (overall point) in accordance with manipulator position, tree mass, we get the data for existing undercarriage frame (UF) of the feller buncher LP-19V and for active undercarriage frame referring to the patent $[07,08]$, which are represented graphically on the Figures.

Figure 5 shows overall point position in respect with manipulator position against the undercarriage frame and the distance to pivot axis of the rotating platform.

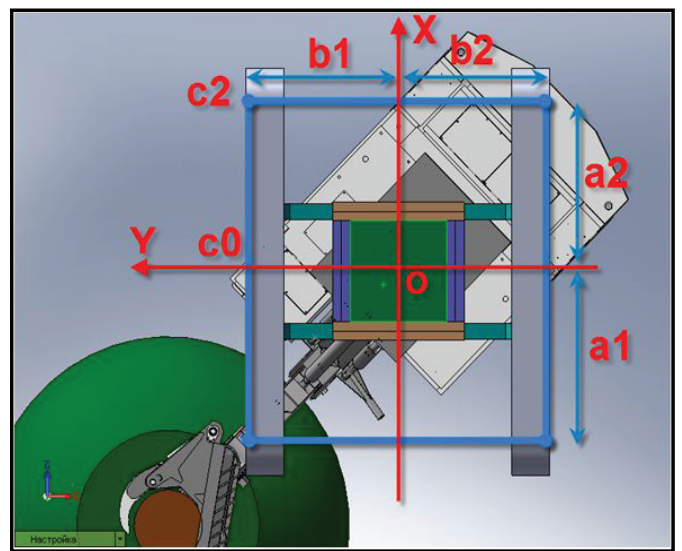

Figure 4. - Overall sector parameters of the advanced LP-19(a) digger suspension system. Bottom view.

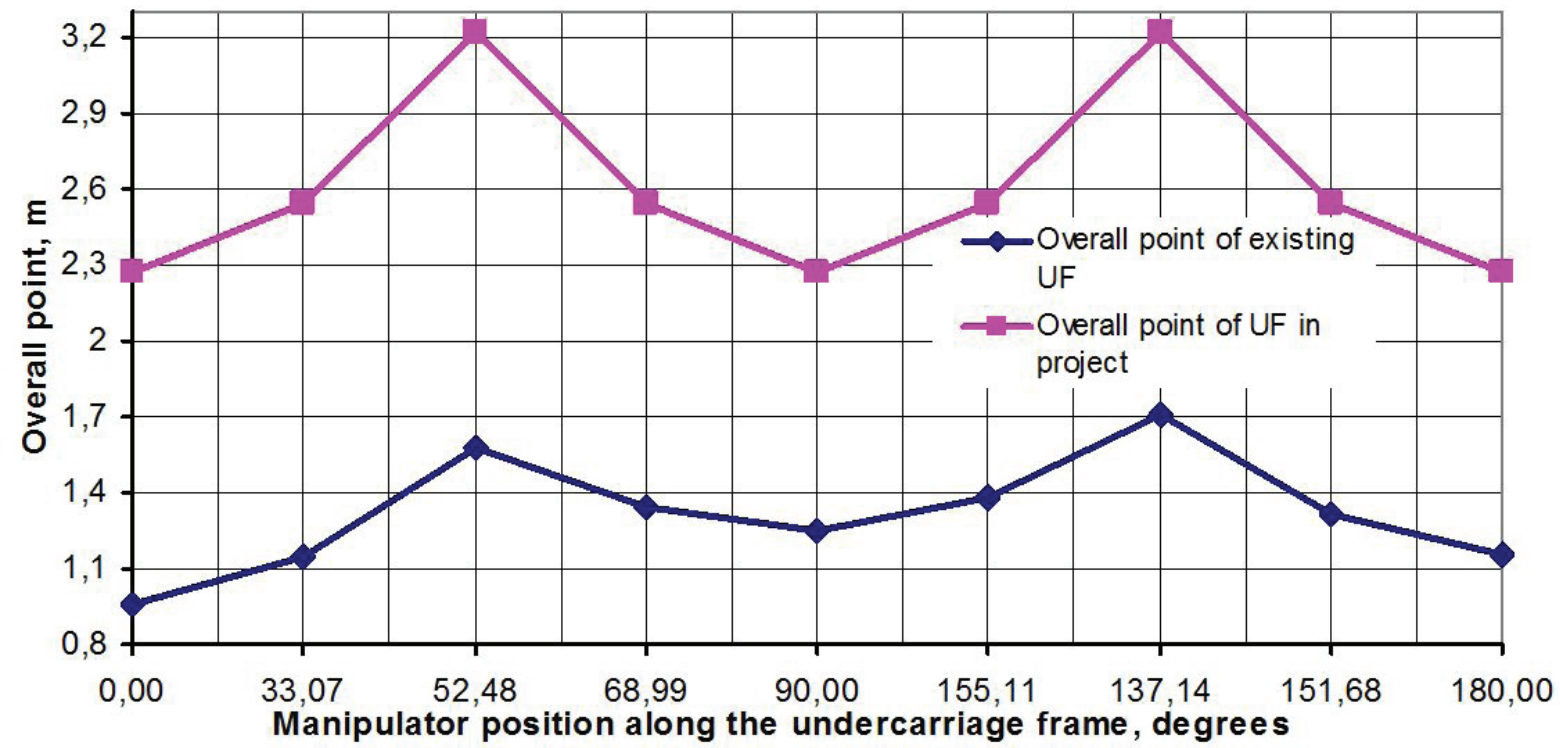

Figure 5: Change of the overall point according to manipulator position against undercarriage frame. 
As it is clear from the diagram this variant of the undercarriage system improves stability of LP$19 \mathrm{~V}$ when it performs technological operations, significantly.

This way, in advanced model, overall point is located farther than pivot axis and for this reason the stability should increase. Let's check this hypothesis.
Figures $6-7$ show moments of overall and of holdup of the machine according to manipulator position if manipulator radius equals 8 meters.

These diagrams demonstrate clearly the improved performance characteristics of the advanced undercarriage frame.

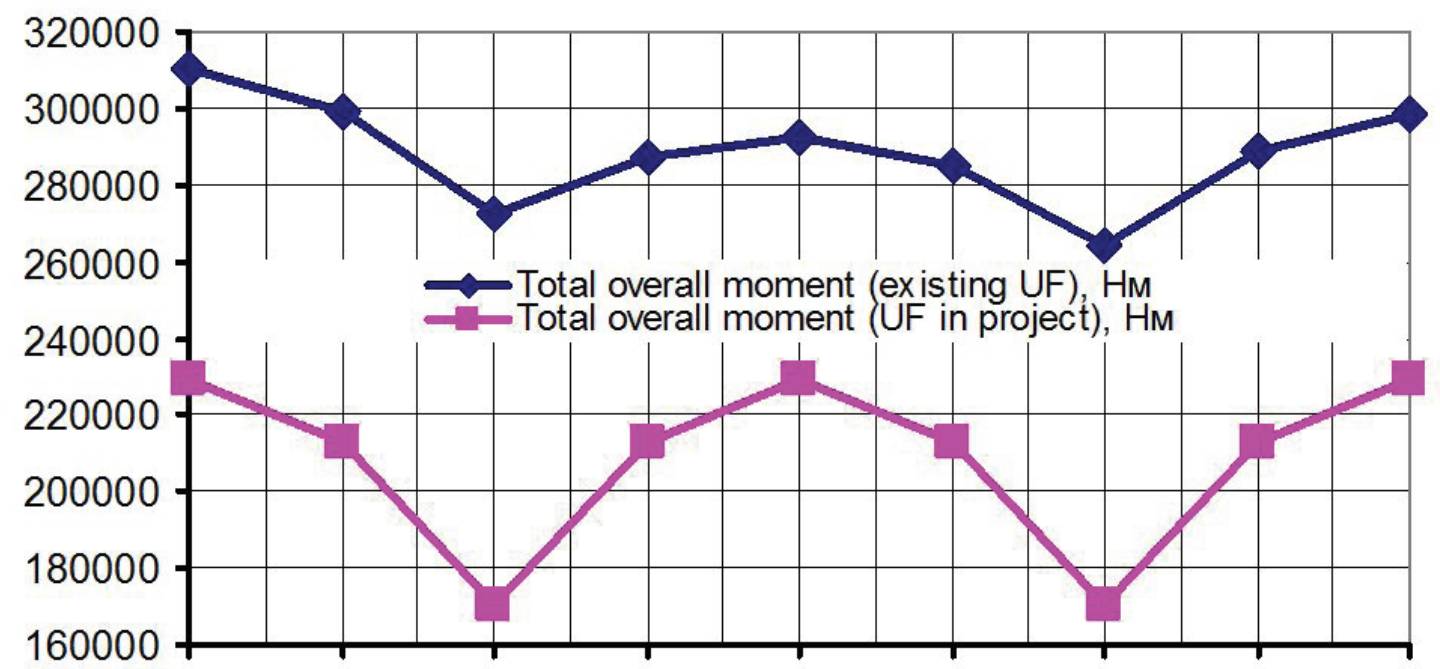

\section{$\begin{array}{lllllllll}0,00 & 33,07 & 52,48 & 68,99 & 90,00 & 155,11 & 137,14 & 151,68 & 180,00\end{array}$} Manipulator position along undercarriage frame, degrees

Figure 6. Change of overall moment according to manipulator position.
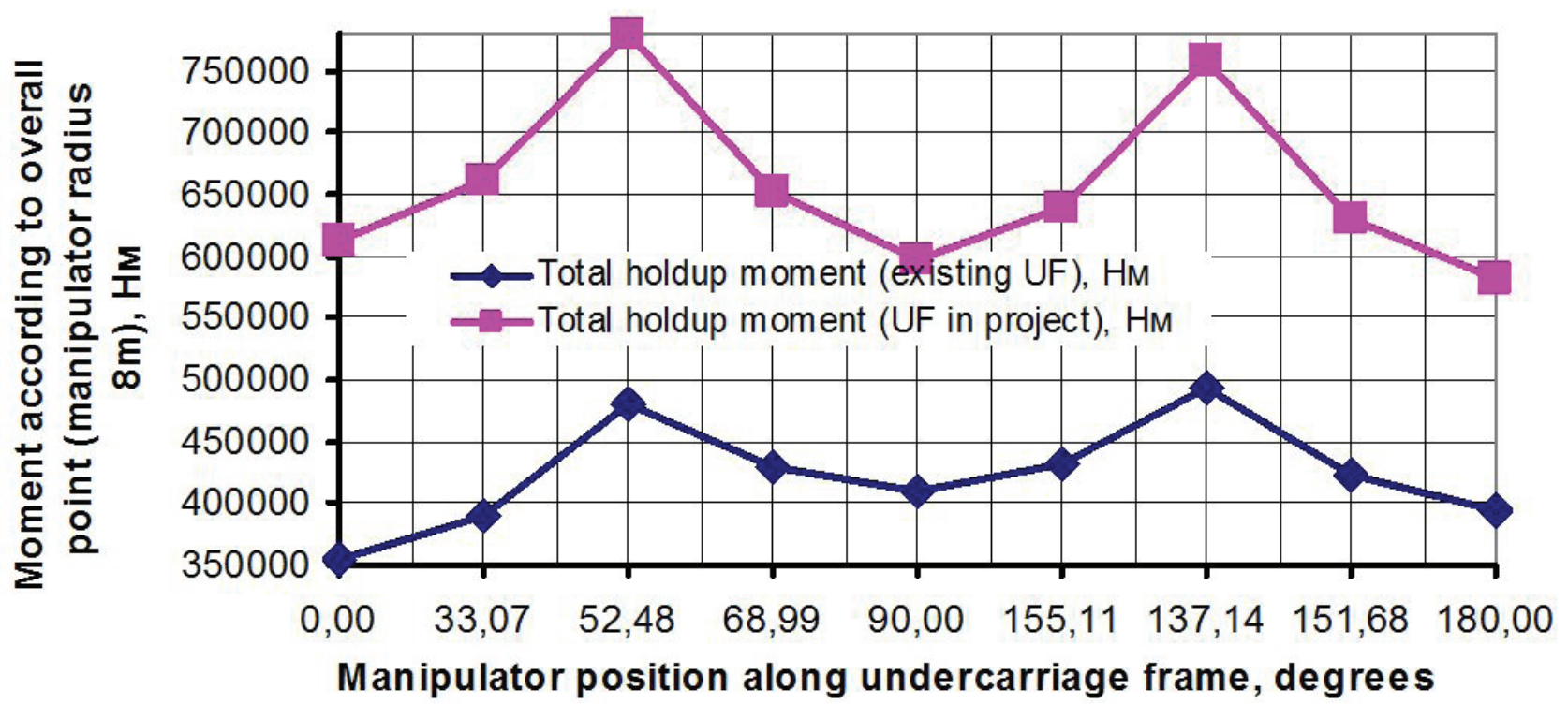

Figure 7. Change of holdup moment of the machine according to manipulator position. 


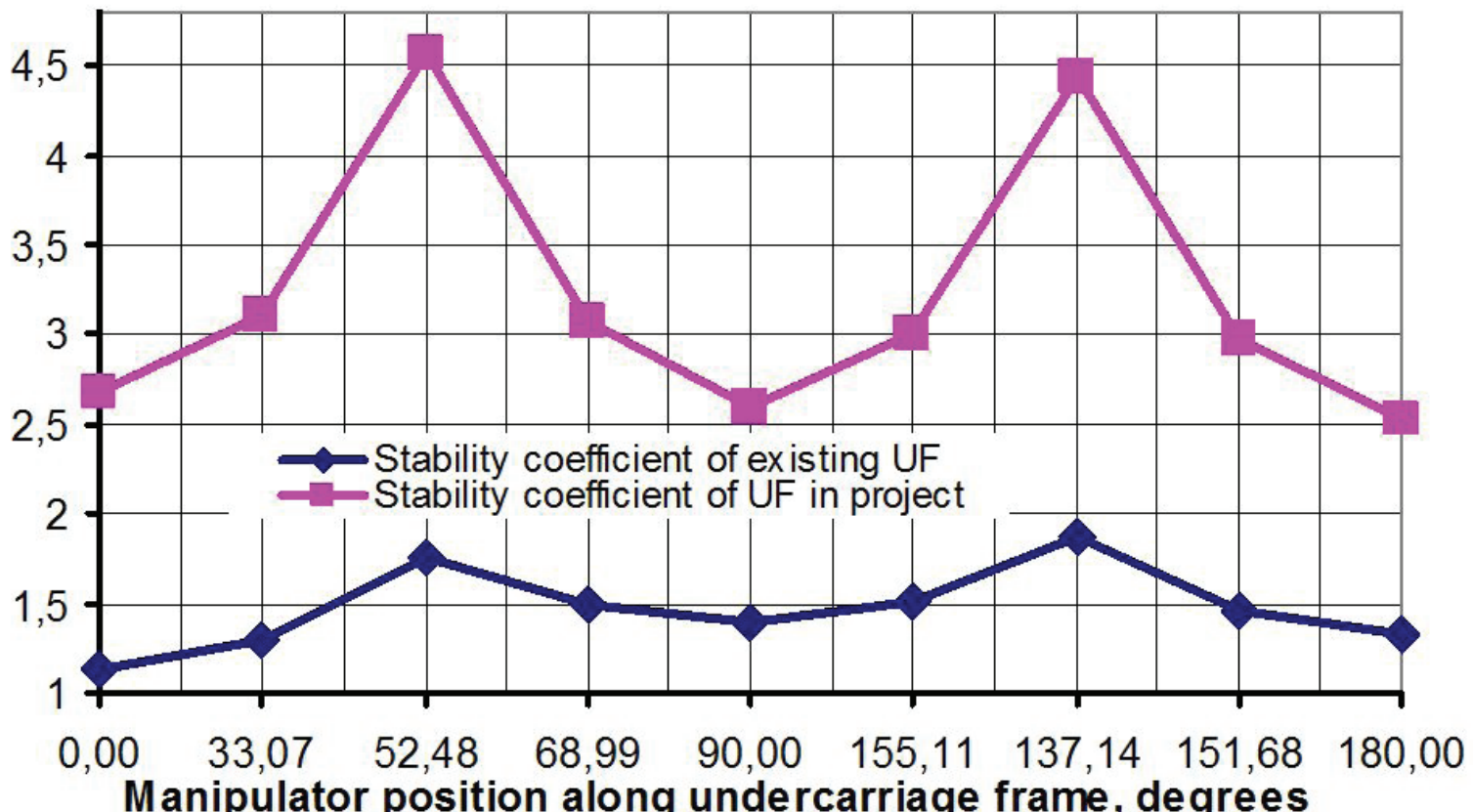

Figure 8 - change of stability coefficient against manipulator position.

Figure 8 represents stability coefficient of a feller buncher while using an existing undercarriage frame and advanced Undercarriage frame. The diagram shows stability non uniformity while moving a tree by means of manipulator's turn. At this, a significant stability is noticed in diagonal manipulator position. So, it can be recommended to install undercarriage frame diagonally about the tree, when cutting trees of a heavy mass. It permits to achieve safe tree felling.

\section{CONCLUSIONS}

1) This paper represents a numerical scheme for moving a tree by means of manipulator turn in statics. The modeling and analysis of the model show its adequacy and opportunity to apply in course of investigation of other systems of manipulator type.

2) It was found that the machine with existing carriage frame possesses stability in profile plane more than $26.5 \%$ higher in comparison with longitudinal plane. For this reason, it is recommended to operators to use manipulator, while working with thick trees, only in profile plane.

3) Active undercarriage is constructed as undercarriage system of digger type, which is common to western machines (TimberPro TL 735, Valmet 445 FXL, CAT 521, John Deere 753J and others) it differs from them due to rigid base for crawler tread.
4) The modeling of the active undercarriage system showed, that current system has stability in transport position in longitudinal plane $17 \%$ higher than in rolling plane. Therefore, it is recommended to operators, working with undercarriage systems of digger type, to use manipulator only in longitudinal plane for thick trees.

5) The modeling of the active undercarriage system in operative position testified that stability of feller buncher grows in longitudinal plane up to $96.2 \%$, in rolling plane up to $49.8 \%$ and in intermediate position up to $193 \%$ in comparison with existing undercarriage system.

6) We propose the active undercarriage system with possibility of track extension, covered by patents № 2491201 and № 127356, Russian Federation. It is considerably superior to existing undercarriage frame of feller buncher LP-19V and allows increase productivity by means of enhancing stability of the machine, which influences psychophysical condition of operator at work.

\section{REFERENCES}

1) Okorokov A.A., Dmitrenko I.E., Skvira E.M., eds. Pravila ustroistva i bezopasnoi ekspluatatsii gruzopod"emnykh kranov [Rules for the Construction and Safe Operation of load-lifting cranes] Moscow, Metallurgiya Publ., 
1) $1984,173 p$.

2) Raschet EO-4124 [EO-4124 calculation] Kovrov, Kovrovskii ekskavatornyi zavod, 1975.

3) Zhiveynov N.N., Karasev G.N., Ustoichivost' ekskavatora (Stability of the excavator) Moscow, Mashinostroenie Publ., 1997, no. 7.

4) Karasev G.N., Stepanov A.A. Analiz ustoichivosti ekskavatora (Analysis of stability of the excavator) Moscow, Stroitel'nye i Dorozhnye mashiny, 1997 - No. 10.

5) Pavlov B.P., Zhiveynov N.N., Karasev G.N. Proektirovanie odnokovshovykh ekskavatorov s primeneniem EVM i SAPR (Design of excavators with one ladle with use of the COMPUTER and SAPR), Krasnoyarsk, Izdvo Krasnoyar. Univ., 1988.

6) Bagautdinov I.N., Shestakov Y.I. Otsenka vliyaniya neploskostnosti opornogo kol'tsa oporno-povorotnogo kruga platformy mashiny LP-19V na napryazhennoe sostoyanie mekhanizma povorota. Izvestiya vuzov Lesnoi zhurnal, 2002 .no. 7, pp 38-44.
7) Bagautdinov I.N., Shestakov Y.I., Loskutov Y.V., Patrakov R.V., Zhilin S.S., Mikhaylov E.E. Sistema khodovaya lesozagotovitel'noi mashiny [Running system forest mashine]. Patent RF, no. 2491201, 2013.

8) Bagautdinov I.N., Shestakov Y.I., Zhelonkin A.A., Tsvetkov S.A., Tsarkov A.G., Bogdanov E.N. Sistema khodovaya lesozagotovitel'noi mashiny [Running system of a forest mashine]. Patent RF, no. 127356, 2013.

9) Valochno-paketiruyushchaya mashina LP19 (raschetnaya zapiska) [Feller Buncher LP-19 tractor (tractor calculations)] Khimki, TsNIIME Publ., 1974, - 358p.

Paper sent to revision: 19.01.2015.

Paper ready for publication: 09.06.2015. 